\title{
Dynamic Yield Strength and Spall Strength of Alumina Short Fiber Reinforced ZL109 Cast Aluminium Alloy
}

\author{
R.Q. Zhang, C.H. Wang, G.M. Zhao and X.W. Zeng \\ Department of Applied Physics, National University of Defence Technology, Changsha, Hunan 410073, \\ P.R. of China
}

\begin{abstract}
This paper describes the results of plate impact experiments conducted on a alumina short fiber reinforced ZL109 cast aluminium alloy. The loading was produced by a $100 \mathrm{~mm}$ bore light gas gun. The metal-matrix composite specimen was backed with a PMMA. Manganin gauges were used to measure the normal stress history at the interface between the specimen and the PMMA. The dynamic yield strength and spall strength of the metal-matrix composite were determined.
\end{abstract}

\section{INTRODUCTION}

Short fiber reinforced metal-matrix composites (MMC) are a class of advanced materials. These composites have extensive potention for the use in aerospace, automotive and telecommunication industries due to their lower densities and superian mechanical properties. It is imperative therefore to study the dynamic mechanical response of such MMC. In this paper, we present our research results on the dynamic yield strength $\left(Y_{d}\right)$ and spall strength $\left(\sigma_{f}\right)$ of a cast aluminum alloy (ZL109) matrix based composite, reinforced

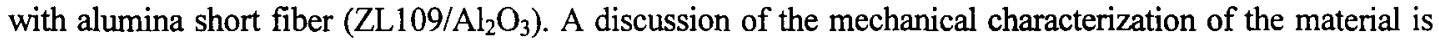
given.

\section{MATERIAL SPECIFICATION}

The nominal composition (wt.\%) of the cast aluminum alloy (ZL109) is: Al bulk, $\mathrm{Si} 12, \mathrm{Mg} 1.2$,

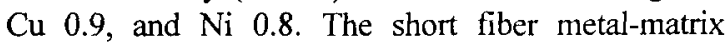
composite ( $\mathrm{ZL109} / \mathrm{Al}_{2} \mathrm{O}_{3}$ ) containes $15 \%$ (in volume) alumina short fiber of average characteric size $7.5 \mu \mathrm{m}$. Optical micrographs (400X) of this composite taken perpendicular and parallel to the direction of the impacted face of the specimen are shown in Figures 1 (a) and (b), respectively. From these micrographs it is evident that the short fiber are randomly distributed,

Table 1.

Statical mechanical properties of the $\mathrm{ZL} 109 / \mathrm{Al}_{2} \mathrm{O}_{3}$

\begin{tabular}{|c|c|}
\hline Young's Modulus $(\mathrm{E})$ & $71 \mathrm{GPa}$ \\
\hline Poisson's Ratio $(v)$ & 0.31 \\
\hline Tensile Strength $\left(\sigma_{\mathrm{b}}\right)$ & $0.12 \mathrm{GPa}$ \\
\hline Compressive Yield Strength $\left(\sigma_{0.2}\right)$ & $0.24 \mathrm{GPa}$ \\
\hline
\end{tabular}
and theorefore the composite could be treated as isotropic material.

Static mechanical properties for $\mathrm{ZL} 109 / \mathrm{Al}_{2} \mathrm{O}_{3}$ are determined by quasi-static tensile and compression tests, which were performed using a material testing machine named WDS-100B. These tests give the static mechanical properties as shown in Table 1. From the observation of the tensile stress-strain response in our 


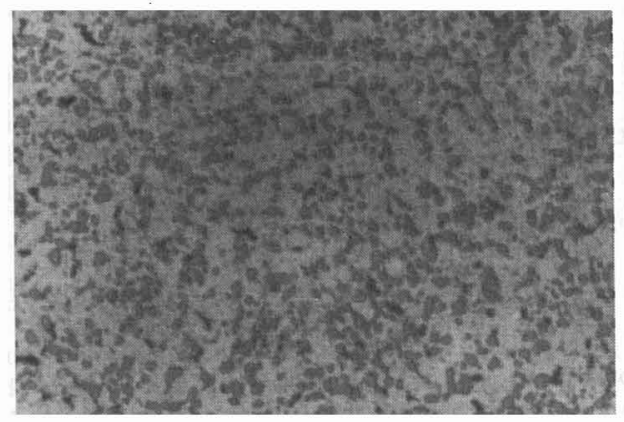

(a)

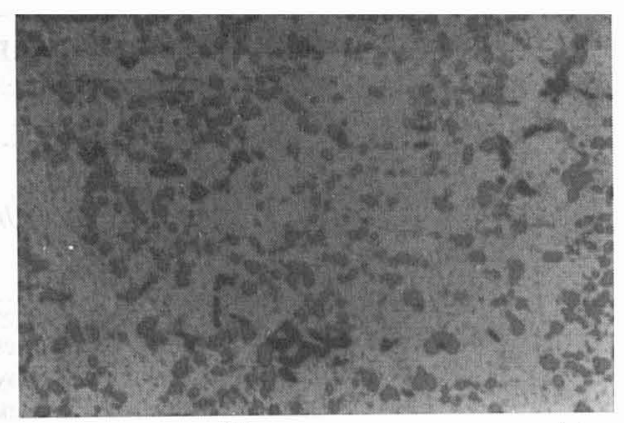

(b)

Figure 1. Optical micrographs (400X) of a $\mathrm{ZL} 109 / 15 \%$ (in Volume) $\mathrm{Al}_{2} \mathrm{O}_{3}$ composite with short fiber, where (a) is the perpendicular view, and (b) is the parallel view.

test, the $\mathrm{ZL109} / \mathrm{Al}_{2} \mathrm{O}_{3}$ appeared as a brittle material, Assuming that the composite $\left(\mathrm{ZL109} / \mathrm{Al}_{2} \mathrm{O}_{3}\right)$ property is uniform in each direction, the bulk moduli $\mathrm{K}$ and shear moduli $\mathrm{G}$ could be calculated as:

$$
\begin{aligned}
& K=\frac{E}{3(1-2 v)}=62.3(G P a) \\
& G=\frac{E}{2(1+v)}=27.1(G P a)
\end{aligned}
$$

Using elastic wave theory, the bulk wave velocity $\left(\mathrm{C}_{b}\right)$ and longitudinal wave velocity $\left(\mathrm{C}_{\mathrm{L}}\right)$ are related to the $K$ and $G$ as $C_{b}{ }^{2}=K / \rho_{0}, C_{L}{ }^{2}=(K+4 G / 3) / \rho_{0}$. With the values for $K$ and $G$ given above and a initial density $\rho_{0}$ of $2.69 \mathrm{~g} / \mathrm{cm}^{3}$, we have $C_{b}=4813 \mathrm{~m} / \mathrm{s}$ and $C_{L}=6050 \mathrm{~m} / \mathrm{s}$, respectively.

\section{EXPERIMENT AND RESULTS}

The plate-impact experiments were performed with the $100 \mathrm{~mm}$ bore light gas gun, at the Laboratory for Shock Wave and Detonation Physics Research, Southwest Institute of Fluid Physics of China. A schematic description of the experimental setup is shown in Figure 2. A $90 \mathrm{~mm}$ in diameter and $2 \mathrm{~mm}$ thick $45^{\sharp}$ steel disk was used as a flyer plate. A $4 \mathrm{~mm}$ thick specimen was backed with a $12 \mathrm{~mm}$ thick PMMA block. The longitudinal stress normal to the plane wave fronts was measured by a manganin gauge situated at the composite/PMMA interface. The gauge was carefully calibrated under shock loading condition. When the shock amplitude is within the range of $0-9 \mathrm{GPa}$, the gauge behaves linearly with piezoresistance coefficient of $2.4 \times 10^{-2} \mathrm{GPa}^{-1}$. The ratio of diameter to thickness of the specimen is 24 , which assures that release waves propagating in from the outer edge of the sample do not have time to change the state of stress (strain) during the experimental measurement.

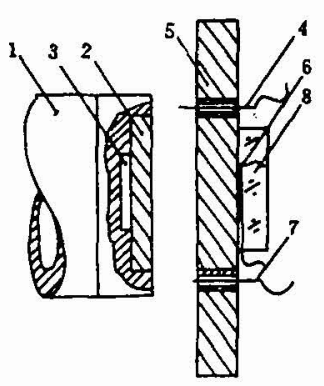

Figure 2. Schematic diagram of the experimental setup, where 1 is the projectile, 2 , the impactor ( $45^{\#}$ steel); 3 , the gap; 4 , the velocity pins; 5 , the target specimen; 6 , the manganin gauge; 7 , the trigger pins ; and 8, the PMMA backing 


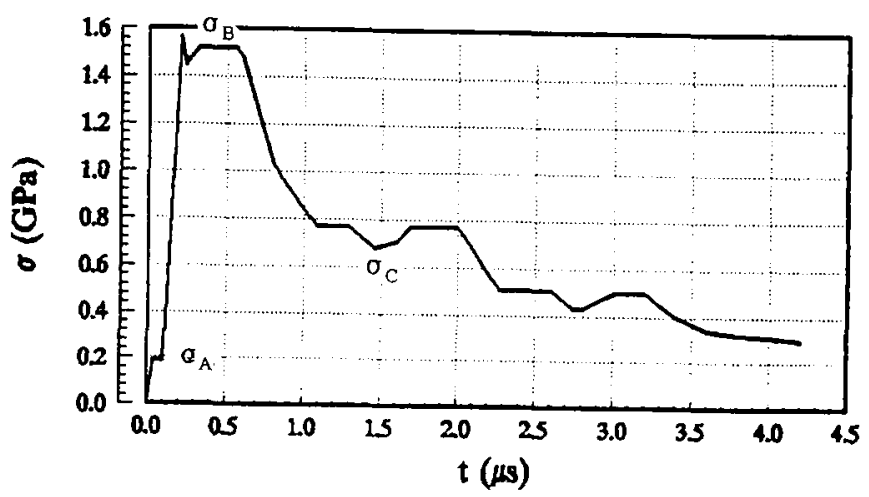

Figure 3. The stress histore at the composite/PMMA interface of a typical experiment at a impacting velocity of $324 \mathrm{~m} / \mathrm{s}$.

A typical stress history at the composite/PMMA interface determined from the gauge recorded is shown in Figure 3. The impact velocity in this experiment is $324 \mathrm{~m} / \mathrm{s}$. In this experiment result, we can see the elastic precursor amplitude is $\sigma_{\mathrm{A}}=0.20 \mathrm{GPa}$, the main shock peak is $\sigma_{\mathrm{B}}=1.52 \mathrm{GPa}$, and the $\sigma_{\mathrm{C}}$ represented spall signal is of $0.75 \mathrm{GPa}$.

In fact, the gauge did not record the stresses in the specimen directly. It only recorded the stresses

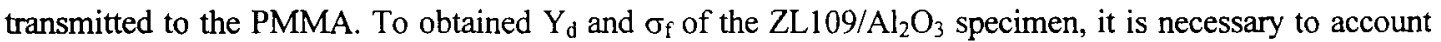
for the acoustic mismatch between the specimen and the PMMA backing. In our planar experimental conditions, the compressive waves propagate forward into the target and back into the impactor are both the elastic-plastic double compressive wave structure. Under linearly elastic-ideal plastic response, the Hugoniot elastic limit $\left(\sigma_{\mathrm{HEL}}\right)$ and maximum compression stress $\left(\sigma_{\mathrm{M}}\right)$ for $\mathrm{ZL} 109 / \mathrm{Al}_{2} \mathrm{O}_{3}$ were calculated according the following expressions:

$$
\begin{aligned}
& \sigma_{H E L}=\frac{\sigma_{A}}{2}\left[1+\frac{\left(\rho_{o} C_{L}\right)_{t}}{\left(\rho_{o} C_{L}\right)_{P}}\right]-\frac{\left(\sigma_{H E L}\right)_{P}}{2}\left[\frac{\left(\rho_{o} C_{L}\right)_{t}}{\left(\rho_{o} C_{b}\right)_{P}}-\frac{\left(\rho_{o} C_{L}\right)_{t}}{\left(\rho_{o} C_{L}\right)_{P}}\right] \\
& \sigma_{M}=\sigma_{H E L}+\frac{\sigma_{B}}{2}\left[1+\frac{\left(\rho_{o} C_{b}\right)_{L}}{\left(\rho_{o} C_{b}\right)_{P}}\right]-\frac{\sigma_{A}}{2}\left[1+\frac{\left(C_{B}\right)_{t}}{\left(C_{b}\right)_{P}}\right]
\end{aligned}
$$

where $\rho_{0}, C_{b}$, and $C_{L}$ are initial density, bulk wave velocity, and longitudinal wave velocity, respectively.

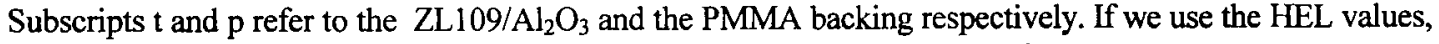
then the dynamic yield strength $Y_{d}$ can be obtained from the well-known relation

$Y_{d}=\frac{1-2 v}{1-v} \sigma_{H E L}$

The spall strength $\sigma_{\mathrm{f}}$ is determined by [1]:

$$
\sigma_{f}=\frac{1}{2}\left\{\sigma_{B}\left[\frac{\left(\rho_{o} C\right)_{t}}{\left(\rho_{o} C\right)_{P}}-1\right]-\sigma_{C}\left[\frac{\left(\rho_{o} C\right)_{t}}{\left(\rho_{o} C\right)_{P}}+1\right]\right\}
$$

where $C=2 C_{b} C_{L} /\left(C_{b}+C_{L}\right)$. It might be noted that in this formula, the elastic-plastic double wave interaction occurring during the fracture process have been ignored. 
Table 2 lists the values of $\sigma_{\mathrm{HEL}}, \mathrm{Y}_{\mathrm{d}}$ and $\sigma_{\mathrm{f}}$ for $\mathrm{ZL} 109 / \mathrm{Al}_{2} \mathrm{O}_{3}$, respectively. In the calculations, we used $v=0.31$ for $\mathrm{ZL109} / \mathrm{Al}_{2} \mathrm{O}_{3}$ as well as $\rho_{0}=1.20 \mathrm{~g} / \mathrm{cm}^{3}, \mathrm{C}_{b}=2240 \mathrm{~m} / \mathrm{s}$ and $C_{2}=2740 \mathrm{~m} / \mathrm{s}$ for PMMA. For comparison with some relevant static mechanical performance parameters, they are also listed in this Table.

Table 2. Some mechanical performance parameters for $\mathrm{ZL} 109 / \mathrm{Al}_{2} \mathrm{O}_{3}$

\begin{tabular}{|c|c|c|c|c|c|c|}
\hline$\sigma_{0.2}(\mathrm{GPa})$ & $\sigma_{\mathrm{b}}(\mathrm{GPa})$ & $\sigma_{\mathrm{HEL}}(\mathrm{GPa})$ & $\mathrm{Y}_{\mathrm{d}}(\mathrm{GPa})$ & $\sigma_{\mathrm{f}}(\mathrm{GPa})$ & $\mathrm{Y}_{\mathrm{d}} / \sigma_{0.2}$ & $\sigma_{\mathrm{f}} / \sigma_{\mathrm{b}}$ \\
\hline 0.24 & 0.12 & 0.54 & 0.30 & 0.74 & 1.25 & 6.17 \\
\hline
\end{tabular}

\section{DISCUSSION}

The dynamic yield and spall experiments have been researched on metal-matrix composites $\mathrm{ZL} 109 / \mathrm{Al}_{2} \mathrm{O}_{3}$, which is observed to posses a higher yield and spall strength than the corresponding uniaxial quasi-static strength (Table 2). This can be explained as the imposition of a hydrostatic stress, the process of damage accumulation is suppressed thereby enhanced ductility and increasing the spall strength of the composite [2].

The results presented in this paper are preliminary. Hixson's experiments showed that the particle shape of the ceramic reinforcement plays a major role to the spall strength of a composite, as well as the volume fraction[3]. It is necessary to determine the effects of alumina short fiber size, sharp, orientation and volume fraction to the spall response of this kind of composite. Micro-structural analysis of virgin and recovered shocked material are also needed, which may indicated the response of inter or intragranular failure. These will be investigated in future.

\section{REFERENCES}

[1] Zeng, Y. J., Jing, F. Q., and Zhang, W. J., Chinese Journal of High Pressure Physics, 6 (1992), 58.

[2] Gray III, G. T., in High-Pressure Science \& Technology 1993, Schmidt, S. C., Shaner, J. W., Swmara, G. A., and Ross, M. Eds. ( AIP Press, 1994) pp1161-1164.

[3] Hixson, R. S., Johnson, J. N. , Gray III, G. T., and Price, J. D. in Shock Comp. of Condensed Matter, 1995, Schmidt, S. C. and Tao, W. C. Eds. (AIP Press, 1996) pp. 555-558. 